\title{
Effect of mechanical strain on gastric cellular migration and proliferation during mucosal healing: role of Rho dependent and Rac dependent cytoskeletal reorganisation
}

T Osada, S Watanabe, H Tanaka, M Hirose, A Miyazaki, N Sato

\begin{abstract}
Background-Various factors affect gastric wound healing. The influence of physical stimulation on gastric mucosal cells during the process of gastric wound healing is not completely understood. Aims-To assess the role of a physical stimulant, in this case mechanical strain, on gastric mucosal restoration.

Methods-Mechanical strain was applied to adherent rat gastric mucosal cells (RGM1) cultured confluently on collagen type I coated silicone elastomer membrane in order to increase the dimension by an average of $5 \%$ and $10 \%$ at 5 cycles/minute for 72 hours after wounding. Repair of the wound was monitored every 12 hours for up to 72 hours using an inverted phase contrast microscope. Cell proliferation was detected using 5-bromodeoxyuridine staining. The cytoskeletal protein actin, a component of focal adhesion plaque protein, vinculin, and the small GTP-binding proteins RhoA and Rac1 were detected by immunohistochemistry in the cells located at the margin of and remote from the wound.
\end{abstract}

Results-The cells located at the margin of the wound showed the greatest migration and proliferation and were found to express more rudimentary lamellipodia and filopodia in the absence of mechanical strain. Vinculin, RhoA, and Rac1 were also strongly expressed in the wound margin. Under conditions of mechanical strain, the speed of migration of cells slowed and fewer proliferating cells were detected around the wound in a strain strength dependent manner. Lamellipodial formation, vinculin, RhoA, and Rac1 were poorly expressed in the same area. However, in cells located more than $1 \mathrm{~mm}$ from the wound edge, cytoskeletal rearrangement, and the expression of vinculin, RhoA, and Rac1 were not influenced by mechanical strain.

Conclusions-Migration and proliferation of RGM1 cells in culture during wound healing were inhibited by mechanical strain, which caused dysfunction of the cytoskeletal and cell adhesion systems. It is suggested that physical stimulants such as mechanical strain may play a role in gastric wound healing in vivo by modifying cellular migration and proliferation. (Gut 1999;45:508-515)
Keywords: gastric wound healing; rat RGM1 cells; migration; proliferation; cell adhesion

It is well known that liquid is emptied from the stomach more rapidly than solid food. ${ }^{1}$ This indicates that the duration of gastric distention after food ingestion is shorter in animals fed on a liquid diet than in those fed on a chow diet. It has been shown that a liquid diet accelerates the repair of gastric ulcer compared with a chow diet. ${ }^{2}$ In the interdigestive state, the cyclic occurrence of phase III contraction is observed. ${ }^{3}$ In the gastric antrum, phasic contraction occurs at almost a constant frequency. Thus the gastric distension and movement after ingestion of food cause mechanical strain on the gastric mucosal cells. However, the effect of mechanical strain on gastric mucosal restoration has not been studied.

In this study, a diploid non-transformed epithelial cell line isolated from normal Wistar rat gastric mucosa (RGM1) was used. ${ }^{4}$ These cells are significantly stimulated to proliferate by both keratinocyte and hepatocyte growth factors $^{5}$ and damaged by acid and pepsin. ${ }^{6}$ Inducible cyclo-oxygenase 2 is essential for the proliferation of these cells. ${ }^{7}$

Gastric mucosal restoration consists of cell migration and proliferation ${ }^{8}$. Adherence of cells to extracellular matrix is mediated through integrins. Integrins cluster while adhering to extracellular matrix in the presence of growth factors and recruit proteins such as vinculin, talin, and paxillin to form focal adhesion complexes, ${ }^{910}$ which regulate cell migration and proliferation. ${ }^{11} 12$

The Rho family is a well known member of the Ras superfamily of small guanosine triphosphatases which exhibit both GDP/GTP binding and guanosine triphosphatase activities. The Rho family regulates signal transduction from receptors in the membrane to a variety of cellular events related to cell morphology, ${ }^{13}$ motility, ${ }^{14}$ cytoskeletal systems, ${ }^{15}$ and tumour invasion. ${ }^{16}$ Rho triggers the formation of contractile stress fibres and focal adhesion complexes in Swiss 3T3 cells. ${ }^{15}$ Rac, a member of the Rho family, induces lamellipodial protrusions and focal complexes in the lamellipodium in the same cells. ${ }^{17}$

Abbreviations used in this paper: RGM1, rat gastric mucosal cells; DMEM/F12, Dulbecco's modified Eagle medium and Ham's F12; BrdU, 5-bromodeoxyuridine; ECM, extracellular matrix. 
We studied the effect of mechanical strain on migration and proliferation of gastric epithelial cells around the gastric mucosal wound in culture during wound healing. Furthermore, the role of mechanical strain on the cytoskeletal system, focal adhesions, and small GTPbinding proteins RhoA and Rac1 was assessed using an in vitro gastric wound repair model. ${ }^{8}$

\section{Materials and methods}

CELL CULTURE

RGM1 cells obtained from Riken Cell Bank (Tsukuba, Japan) were cultured in a $1: 1$ mixture of Dulbecco's modified Eagle medium and Ham's F12 medium (DMEM/F12) (Life Technologies, New York, New York, USA) supplemented with $100 \mathrm{IU} / \mathrm{ml}$ penicillin, 100 $\mu \mathrm{g} / \mathrm{ml}$ streptomycin, $0.25 \mu \mathrm{g} / \mathrm{ml}$ amphotericin B and $10 \%$ fetal calf serum (Life Technologies) in a $5 \% \mathrm{CO}_{2} /$ air humidified atmosphere at $37^{\circ} \mathrm{C}$. All the experiments were carried out before the 20th passage of the cells.

APPLICATION OF STRAIN TO CULTURED CELLS RGM1 cells were cultured in six-well collagen type I coated silicone elastomer bottomed culture plates (BioFlex plate; Flexcell Corp, McKeesport, Pennsylvania, USA). Cells were subjected to mechanical deformation with the Flexercell Strain Unit (Flexcell Corp). The stress unit, described and characterised previously, ${ }^{18} 19$ consists of a vacuum unit linked to a valve controlled by a computer program. When a precise vacuum level is applied to the system, the culture plate bottoms are deformed by a known percentage, which is translated to the cultured cells, resulting in strain. The force of the strain on the membrane during stretch at various vacuum levels has been calculated mathematically. ${ }^{20}$ The force on attached cells is primarily in one axis, almost a radial strain. Furthermore, there is heterogeneity of strain across the membrane; cells in the periphery of the membrane experience high strain, whereas those in the centre experience relatively low strain. In this set of experiments, the flexible membrane bottoms were subjected to deformation by -3.2 and $-8.2 \mathrm{kPa}$ vacuum at 5 cycles/minute (six seconds of stretch alternating with six seconds of relaxation). Therefore the dimension of the cells adhering to the collagen type I coated silicone elastomer membrane was increased by an average of 5\% (5\% strain group) and $10 \%$ (10\% strain group) in parallel with the radius of the monolayer (see fig 7). Controls were grown on the same plates but not subjected to mechanical strain. Cell viability after strain treatment was constantly checked by trypan blue staining. Cells did not show any significant damage after being strained for 72 hours.

ARTIFICIAL WOUNDING AND QUANTITATIVE EVALUATION OF EFFECT OF MECHANICAL STRAIN RGM1 cells were inoculated on to BioFlex plates at a concentration of $3 \times 10^{5} /$ well. The cells had formed complete monolayers 72 hours after cell inoculation. The medium for the cultured cells was changed to serum-free medium (DMEM/F12) for 24 hours. An artifi- cial wound, consisting of a uniform sized cell-free area $\left(2.0 \mathrm{~mm}^{2}\right)$, was made by cell denudation using a pencil-type mixer with a rotating silicone tip as reported previously. ${ }^{8}$ The wounds were made at a constant distance $(10 \mathrm{~mm})$ from the centre of a $35 \mathrm{~mm}$ diameter well to avoid strain heterogeneity. Culture medium was then replaced with the same medium containing $1 \%$ fetal calf serum. Plates were placed on the Flexercell Strain Unit in the incubator and subjected to mechanical strain. In parallel experiments, other BioFlex plates not subjected to mechanical strain served as controls. Wound repair was monitored every 12 hours using an inverted phase contrast microscope (Nikon TMD; Nikon Tokyo, Japan) up to 72 hours. The cell-free area was measured with an IBASII computer image analyser (Carl Zeiss, Oberkochen, Germany).

\section{BROMODEOXYURIDINE STAINING}

Proliferating cells were stained by indirect immunohistochemical methods using monoclonal anti-bromodeoxyuridine (BrdU) (Sigma Chemical Co, St Louis, Missouri, USA) ${ }^{21}$ antibody. Three groups were compared. In the first group, BrdU was added to the culture medium at a concentration of $10 \mu \mathrm{g} / \mathrm{ml}$ immediately after the wound was made, and this was followed by incubation for 24 hours (0-24 hour group). In the second group, BrdU was added 24 hours after wound formation and incubation was continued for 24 additional hours (24-48 hour group). In the third group, BrdU was added 48 hours after wound formation and incubation was continued for 24 hours (48-72 hour group). Samples were stained for BrdU using anti-BrdU monoclonal antibody (Novocastra Lab Ltd, Newcastle upon Tyne, UK) by standard techniques. The BrdU labelling index (number of BrdU positive cells/total number of cells per unit area $\left(0.12 \mathrm{~mm}^{2}\right)$, expressed as a percentage) in controls and groups subjected to mechanical strain was calculated.

IMMUNOFLUORESCENCE MICROSCOPY

All solutions were prepared in phosphate buffered saline. Cells were thoroughly rinsed in phosphate buffered saline between stages, and incubations were performed at room temperature. For actin staining, cells were fixed with methanol for three minutes. F-actin was detected by rhodamine phalloidin (Molecular Probes, Eugene, Oregon, USA) staining. ${ }^{22}$

For the staining of vinculin, an adhesion plaque protein, ${ }^{23}$ cells were fixed with $4 \%$ paraformaldehyde and permeabilised using $0.1 \%$ Triton-X 100; they were then incubated overnight with a 1:50 dilution of monoclonal mouse vinculin antibody (Novocastra Lab Ltd). Cells were incubated with fluorescein isothiocyanate conjugated goat anti-mouse and then donkey anti-goat antibodies.

For RhoA and Rac1 staining, cells were fixed with ethanol for three minutes at $-20^{\circ} \mathrm{C}$. They were then incubated overnight with the primary antibodies, 1:10 diluted monoclonal mouse anti-RhoA (26C4; Santa Cruz Biotechnology, Santa Cruz, California, USA) and rabbit anti-Rac1 (C-14; Santa Cruz 


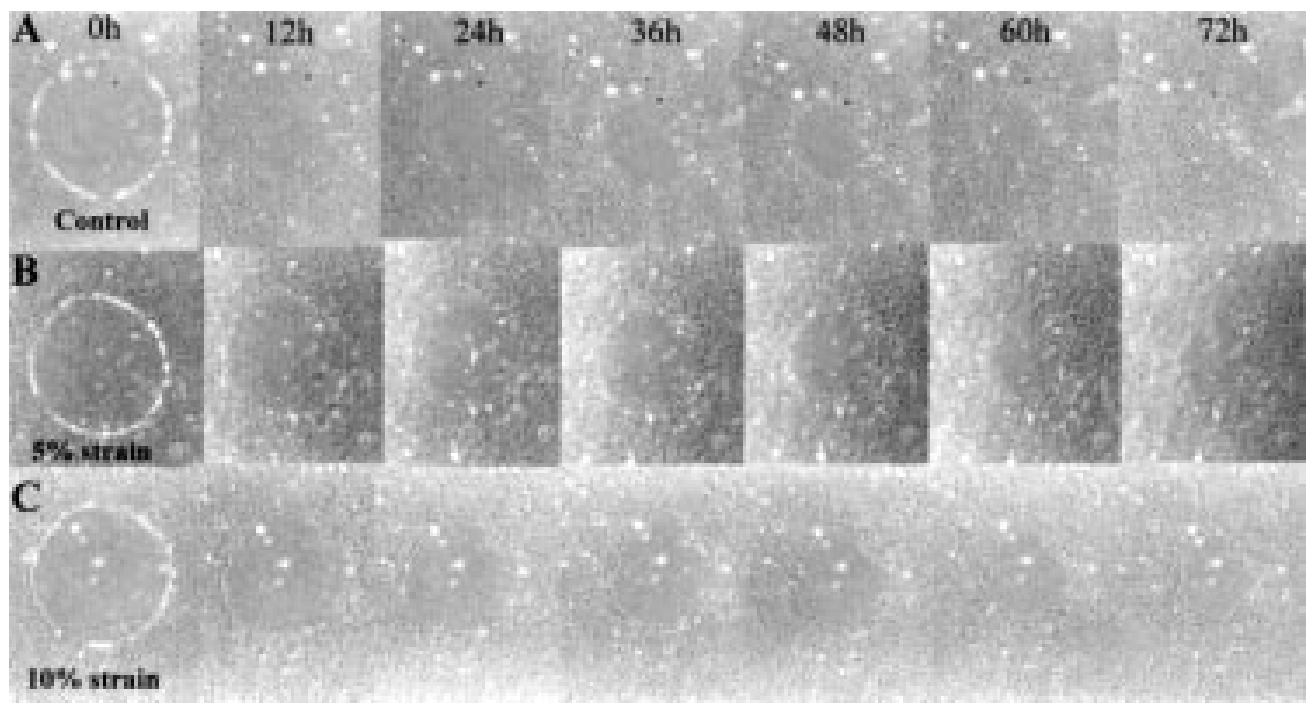

Figure 1 Phase contrast photomicrographs showing the process of wound restoration. In the control cultures $(A)$ (not subjected to strain), mucosal restoration was complete at 72 hours after wounding. In the 5\% (B) and $10 \%$ (C) strain groups, the process of restoration was retarded by mechanical strain in a strength dependent manner. Original magnification $\times 40$.

Biotechnology). Secondary antibodies used were fluorescein isothiocyanate conjugated goat anti-mouse for RhoA (Santa Cruz Biotechnology) and goat anti-rabbit for Rac1 (Santa Cruz Biotechnology).

Samples were evaluated and their appearance was recorded on a Zeiss Axiophot microscope (Carl Zeiss) with Ektachrome Dyna 400 films (Eastman Kodak Co, Rochester, New York, USA).

\section{STATISTICAL ANALYSIS}

Results were expressed as mean (SD). Statistical analysis was performed using analysis of variance and unpaired Student's $t$ test. A level of $p<0.05$ was accepted as statistically significant (two-tailed).

\section{Results}

GASTRIC EPITHELIAL RESTORATION WITH AND WITHOUT MECHANICAL STRAIN

An artificial wound of constant size was made by mechanical cell denudation using a rotating silicone tip. The cell-free area was $2.00 \mathrm{~mm}^{2}$ at wounding. In controls, the size of the cell-free area decreased gradually and was completely closed 72 hours after wound formation (fig 1). In the groups subjected to $5 \%$ and $10 \%$ mechanical strain, wound healing was slower than in controls. Table 1 shows the healing rate in controls and $5 \%$ and $10 \%$ strain groups. The differences among controls and the 5\% strain and $10 \%$ strain groups were statistically significant at 24 hours $(\mathrm{p}<0.05)$. Wound repair was inhibited by mechanical strain in a strength dependent manner. The difference between $5 \%$ and $10 \%$ strain was statistically significant from 36 hours after wounding $(\mathrm{p}<0.05)$ (table 1).

BROMODEOXYURIDINE STAINING

Figure 2 shows BrdU positive cells in controls (fig 2A,B,C) and cells subjected to $10 \%$ mechanical strain (fig $2 \mathrm{D}, \mathrm{E}, \mathrm{F}$ ). In the process of wound healing, BrdU positive cells were detected around the wound in the $0-24$ hour group (fig 2A,D). The number of BrdU positive cells increased gradually, peaked in the 24-48 hour group (fig 2B,E), and then decreased (fig $2 \mathrm{C}, \mathrm{F}$ ) in both the control and $10 \%$ strain groups. The BrdU labelling index (table 2) was not significantly different between the control group and groups subjected to mechanical strain until 24 hours, but it was significantly lower in the 24-48 hour group and the 48-72 hour group than in controls. The labelling index in the control group was about twofold higher than that of the $10 \%$ strain group and about 1.5-fold higher than that of the 5\% strain group in the 24-48 hour group. The difference between $5 \%$ and $10 \%$ strain was significant from 24 to 72 hours after wounding. Detection of BrdU positive cells decreased in a strain strength dependent manner around the wound. In this study, BrdU positive cells were hardly detected in cells located more than $1 \mathrm{~mm}$ from the wound edge during wound healing in both control and experimental groups (data not shown).

Table 1 Effect of mechanical strain on gastric epithelial restoration over time

\begin{tabular}{|c|c|c|c|c|c|c|c|}
\hline \multirow[b]{2}{*}{ Conditions } & \multicolumn{7}{|c|}{ Size of cell-free area $\left(\mathrm{mm}^{2}\right)$} \\
\hline & 0 hours & 12 hours & 24 hours & 36 hours & 48 hours & 60 hours & 72 hours \\
\hline Control & $2.02(0.05)$ & $1.47(0.10)$ & $1.21(0.05)$ & $0.83(0.05)$ & $0.54(0.06)$ & $0.20(0.06)$ & $0.03(0.05)$ \\
\hline $5 \%$ strain & $2.01(0.06)$ & $1.57(0.05)$ & $1.39(0.08)^{\star}$ & $1.11(0.08)^{\star}$ & $0.82(0.05)^{\star}$ & $0.60(0.10)^{\star}$ & $0.43(0.06)^{\star}$ \\
\hline $10 \%$ strain & $2.03(0.05)$ & $1.64(0.10)$ & $1.50(0.05)^{\star}$ & $1.27(0.09)^{\star} \dagger$ & $1.06(0.08)^{\star} \dagger$ & $0.87(0.08)^{\star} \dagger$ & $0.73(0.10)^{\star} \dagger$ \\
\hline
\end{tabular}

Data are expressed as mean (SD) from six separate experiments.

${ }^{\star} \mathrm{p}<0.05$ versus control; $t \mathrm{p}<0.05$ versus $5 \%$ strain. 

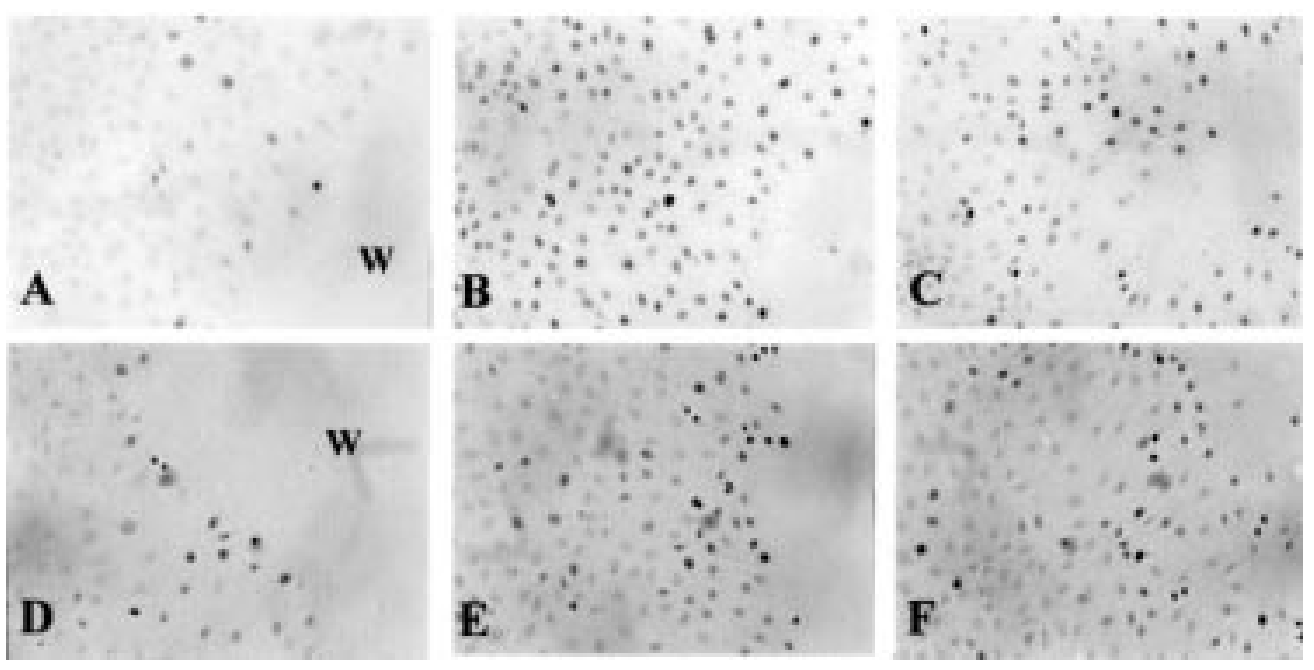

Figure 2 Photomicrographs showing bromodeoxyuridine (BrdU) positive proliferative cells during restoration after wounding. In the control $(A-C)$ and $10 \%$ strain $(D-F)$ groups, they were detected around the margin of the wound. Their number was highest in the 24-48 hour group $(B$ and $E)$ and then decreased in the 48-72 hour group $(C$ and $F)$. Fewer $B r d U$ positive cells were detected in the $10 \%$ strain groups than in controls, but the difference was not statistically significant until 24 hours ( $A$ and D). W, artificial wound. Original magnification $\times 200$.
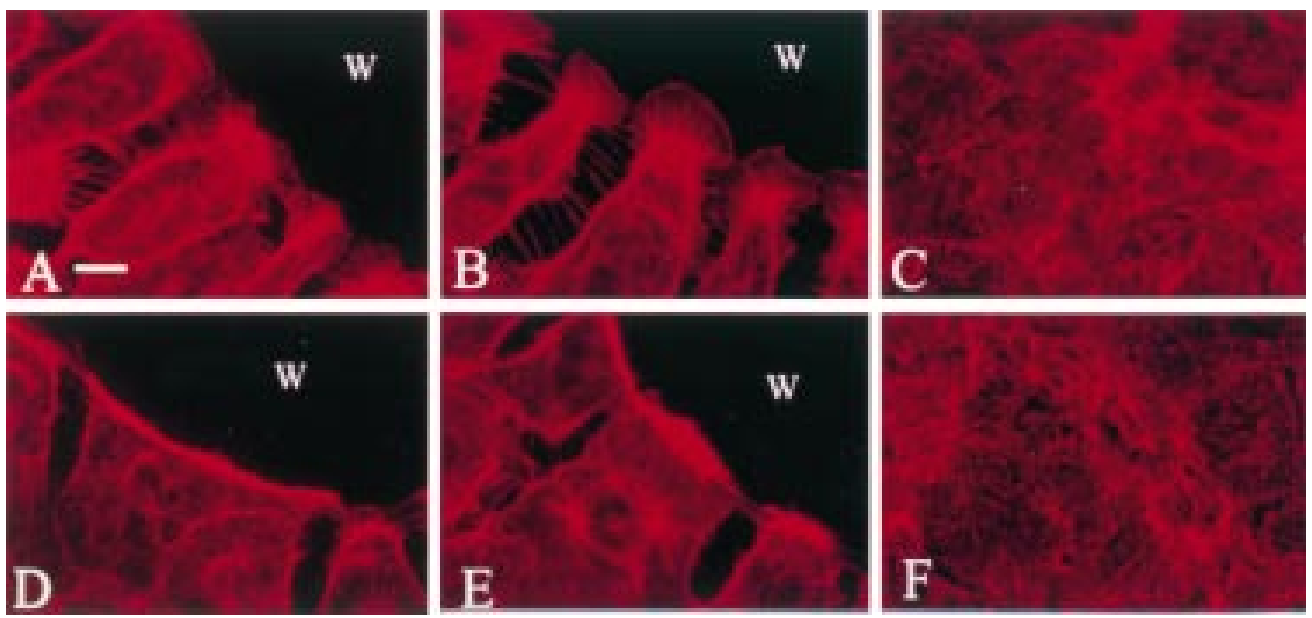

Figure 3 Fluorescence photomicrographs showing actin staining at the margin of the wound and remote from the wound edge. In the control, widely spread lamellipodia and many filopodia were observed at 24 hours (A) and 48 hours (B) at the margin of the wound. In the $10 \%$ strain group, few lamellipodia and filopodia were observed at 24 hours (D) and 48 hours $(E)$ at the same place. In cells remote from the wound edge, actin formation was similar in the control (C) and $10 \%$ strain group $(F)$ at 24 hours. W, artificial wound. Bar $=5 \mu \mathrm{m}$.

ACTIN STAINING

Polymerised actin was stained in the control group and the $10 \%$ strain group 24 and 48 hours after wounding. In controls, cells located at the margin of the wound formed lamellipodia and filopodia at both 24 and 48 hours (fig $3 \mathrm{~A}, \mathrm{~B})$. Specific actin fluorescence was more intense at 48 hours than at 24 hours in the lamellipodia formed in the cells at the edge of the wound. In cells treated with $10 \%$ strain, specific fluorescence for actin was rarely detected in the lamellipodia at the same time

Table 2 Effect of mechanical strain on gastric epithelial cell proliferation during restoration

\begin{tabular}{llll}
\hline & \multicolumn{2}{l}{ Labelling index } & \\
\cline { 2 - 4 } Conditions & 0-24 hours & 24-28 hours & $48-72$ hours \\
\hline Control & $11.94(2.48)$ & $80.72(2.15)$ & $51.20(2.63)$ \\
$5 \%$ strain & $9.27(1.67)$ & $54.05(1.35)^{\star}$ & $47.05(4.61)$ \\
$10 \%$ strain & $11.77(1.82)$ & $44.00(2.63)^{\star} \dagger$ & $35.77(2.40)^{\star} \dagger$ \\
\hline
\end{tabular}

Data are expressed as mean (SD) from six separate experiments.

Labelling index (\%) is bromodeoxyuridine positive cells/total cells in fields.

${ }^{\star} \mathrm{p}<0.05$ versus control; $\nmid \mathrm{p}<0.05$ versus $5 \%$ strain. period (fig 3D,E). The shape of the control cells was more elongated, and the gap between cells was wider compared with cells subjected to $10 \%$ strain at both 24 and 48 hours. The appearance of stress fibres in the cytoplasm was not significantly different between controls and cells subjected to $10 \%$ strain at both 24 and 48 hours. On the other hand, in cells located more than $1 \mathrm{~mm}$ from the wound edge, actin fibre formation was not different between the control and the $10 \%$ strain group (fig $3 \mathrm{C}, \mathrm{F}$ ).

DISTRIBUTION OF FOCAL ADHESION PLAQUE In controls, intense vinculin fluorescence was observed in the cells located at the margin of the wound, especially at the edge of the cells located around the wound, at both 24 and 48 hours (fig 4A,B). However, in the $10 \%$ strain group, fewer vinculin positive cells were observed at the margin of the wound, especially at 48 hours (fig $4 \mathrm{D}, \mathrm{E})$. The distribution and intensity of vinculin in cells remote from the 

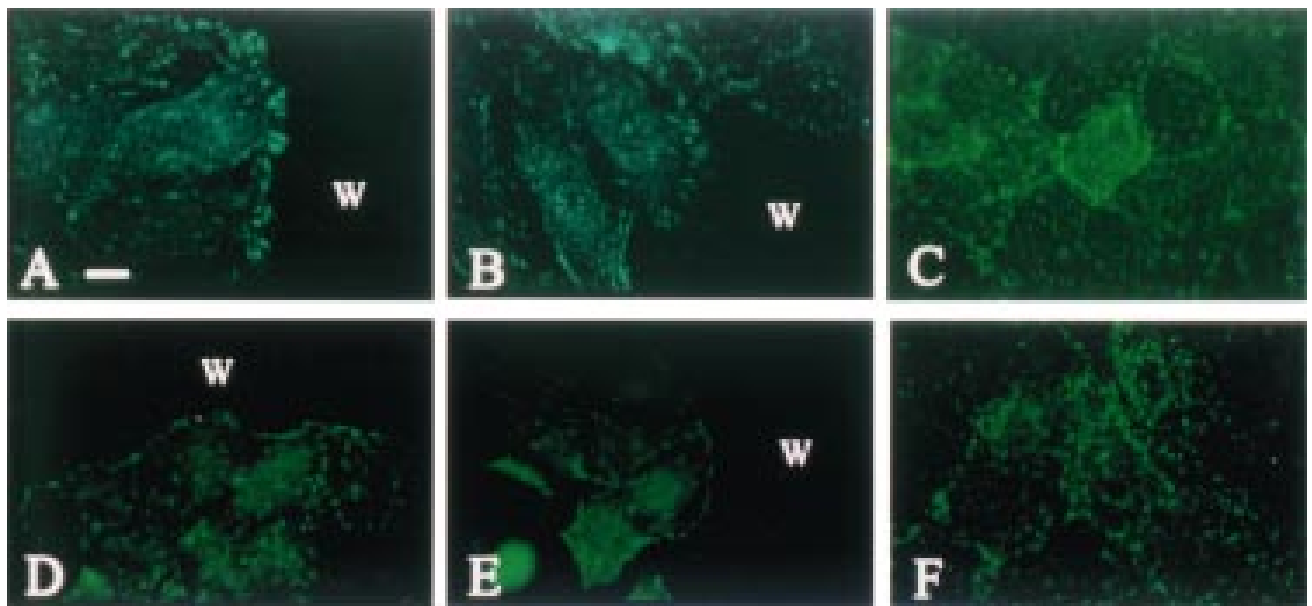

Figure 4 Fluorescence photomicrographs showing vinculin staining at the margin of the wound $(A, B, D, E)$ and remote from the wound edge $(C, E)$. In the control, many vinculin positive cells were observed, and vinculin staining was especially intense at the edge of cells around the wound at 24 hours $(A)$ and 48 hours $(B)$. In the $10 \%$ strain group, they were not readily apparent in the same area at 24 hours (D) and 48 hours (E). In cells remote from the wound edge, the distribution and intensity of vinculin were similar in the control $(C)$ and $10 \%$ strain group $(F)$ at 24 hours. W, artificial wound. Bar $=$ $5 \mu \mathrm{m}$.
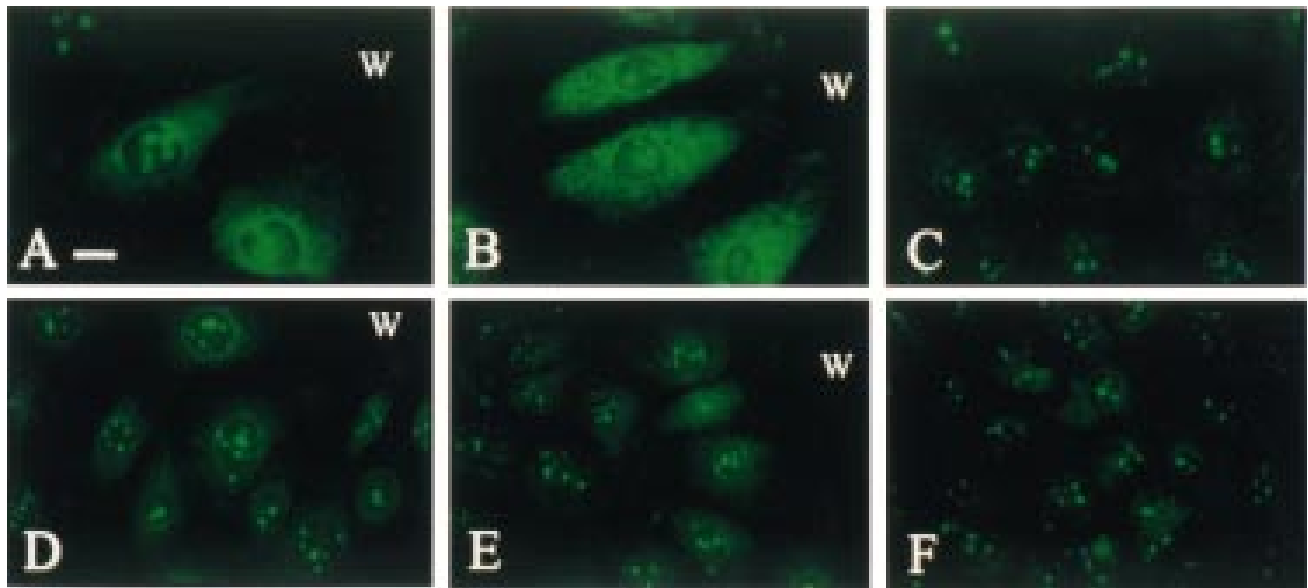

Figure 5 Fluorescence photomicrographs showing Rho $A$ staining at the margin of the wound $(A, B, D, E)$ and remote from the wound edge $(C, F)$. Rho $A$ was more intensely stained in cells located at the margin of the wound $(A, B)$ than in areas remote from the wound $(C)$ in the control. At the margin of the wound, Rho $A$ was more intensely stained in the control $(A, B)$ than in the $10 \%$ strain group $(D, E)$ at both 24 hours $(A, D)$ and 48 hours $(B, E)$. In cells remote from the wound edge, Rho $A$ was similarly stained weakly both in the control $(C)$ and $10 \%$ strain group $(F)$ at 24 hours. W, artificial wound. Bar $=5 \mu \mathrm{m}$.

wound edge was similar in the control and $10 \%$ strain groups (fig $4 \mathrm{C}, \mathrm{F}$ ).

RhOA AND Rac1 STAINING

RhoA and Racl were stained in the control group and in the $10 \%$ strain group 24 and 48 hours after wounding. In controls, intense RhoA and Rac1 staining was observed in cells located at the margin of the wound. RhoA was detected homogeneously in cytoplasm by immunofluorescence staining (fig 5). Rac1 was detected in cytoplasm surrounding the nucleus (fig 6). When the control group and the 10\% strain group were compared, RhoA and Rac1 were much more intensely stained in control cells than in the $10 \%$ strain group, especially in cells located at the margin of the wound, at both 24 and 48 hours after wounding (fig 5A,B and $6 \mathrm{~A}, \mathrm{~B}$ ). Furthermore, specific intensity for both RhoA and Rac1 was stronger at 48 than at 24 hours after wounding. However, in cells located more than $1 \mathrm{~mm}$ from the wound edge, RhoA and Racl were weakly stained in both the control group and the $10 \%$ strain group (fig $5 \mathrm{C}, \mathrm{F}$ and $6 \mathrm{C}, \mathrm{F})$.

\section{Discussion}

Mechanical strain was applied to RGM1 cells using a Flexercell strain unit with a frequency of 5 cycles/minute. The frequency of gastric peristaltic movement is 3 cycles/minute in $\operatorname{man}^{2425}$ and 5 cycles/minute in dog. ${ }^{26}{ }^{27}$ In rats, gland luminal pressure oscillates with a frequency of 4-6 cycles/minute. ${ }^{28}$ We believe that our regimen corresponds to gastric peristaltic movement.

We have created a restoration model using primary cultured gastric mucosal cells that provides quantitative data. ${ }^{29-32}$ In the present study using a modification of this model in cultured RGM1 cells, the effect of mechanical strain on migration, proliferation, and the cytoskeletal system of gastric epithelial cells was evaluated. Mucosal restoration consists of two steps, early stage cell migration (restitution), followed by both proliferation and 

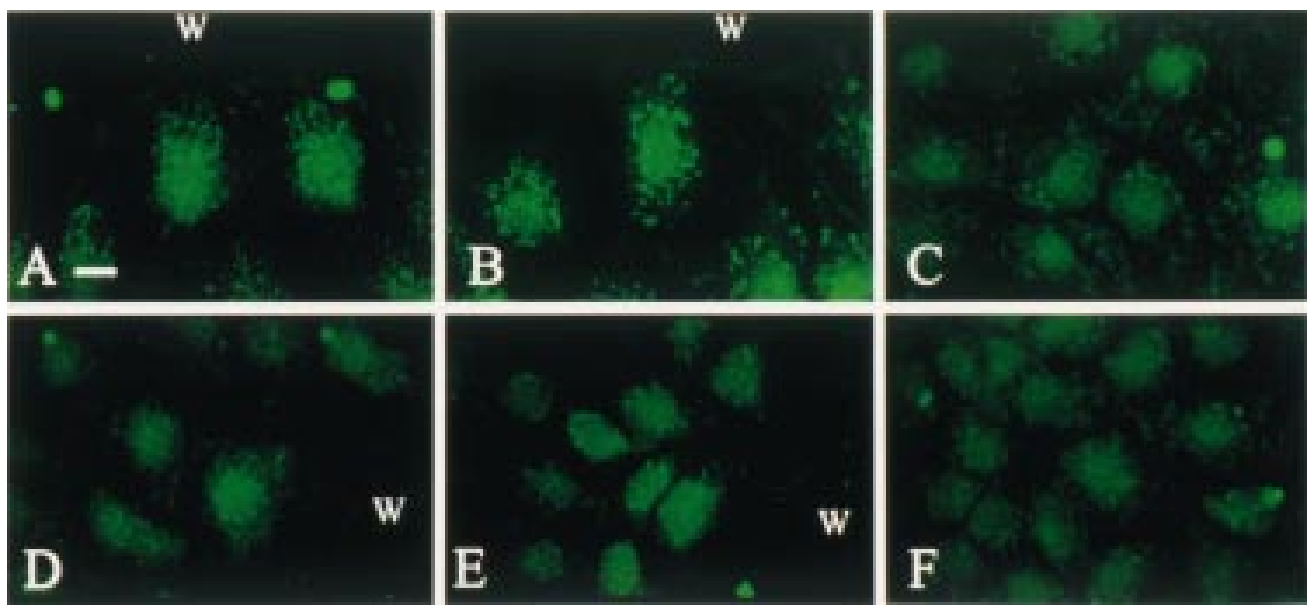

Figure 6 Fluorescence photomicrographs showing Rac1 staining at the margin of the wound $(A, B, D, E)$ and remote from the wound edge $(C, F)$. Rac1 was more intensely stained in cells located at the margin of the wound $(A, B)$ than in areas remote from the wound $(C)$ in the control. At the margin of the wound, Rac1 was apparently more stained in the control $(A, B)$ than in the $10 \%$ strain group $(D, E)$ at both 24 hours $(A, D)$ and 48 hours $(B, E)$. In cells remote from the wound edge, Rac1 was similarly weakly stained both in the control $(C)$ and $10 \%$ strain group $(F)$ at 24 hours. W, artificial wound. Bar $=5 \mu \mathrm{m}$.

restitution in primary cultured gastric mucosal cells around the wound. In cells located more than $1 \mathrm{~mm}$ from the wound edge, the rate of migration of gastric epithelial cells was very low and cell proliferation was hardly detected at all during wound healing. ${ }^{32}$ In the early stage (0-24 hours), cell migration is the dominant process. Under normal conditions, the cell-free area became about $60 \%$ of the original wound size in the first 24 hours. However, it reached only $70 \%$ in the $5 \%$ strain group and $75 \%$ in the $10 \%$ strain group. As the BrdU labelling index was similar for these three groups, the difference in the speed of restoration among the three groups must have been caused by a difference in the speed of cell migration. After 24 hours of incubation, cell proliferation was considerably increased, and the BrdU labelling index was more than $80 \%$. However, in cells subjected to mechanical strain, the wound was not covered at 72 hours. After 24 hours of stimulation, the BrdU labelling index was decreased to $68 \%$ of control values in the $5 \%$ strain group and $55 \%$ in the $10 \%$ strain group. Thus these studies show that mechanical strain inhibited both migration and proliferation of RGM1 cells around the wound.

However, the effect of repetitive strain on intestinal epithelial Caco-2 cell monolayers is to promote proliferation in a strain strength dependent manner. ${ }^{33}$ These findings are the opposite of ours. RGM1 cells are of gastric epithelial origin, however, whereas the Caco-2 cells are of intestinal origin. The differences between the Caco-2 and RGM1 cells may be the result of differences in species and differences between non-transformed and transformed cell lines. Caco-2 cells are a human colonic cancer derived epithelial cell line. Moreover our experiments were assessed under the influence of mechanical strain on wound healing. It is not unlikely that mechanical strain stimulates proliferation in Caco-2 cells whereas it inhibits cell migration and proliferation in RGM1 cells. In our study, migration and proliferation were assessed and compared between cells located close to the wound and remote from the wound. The cells located on the edge of the wound lose their neighbouring cells at wounding. The cells lose cell-cell contact and change their cell polarity, possibly because of the cytoskeletal derangement. Then, the cells were stimulated to migrate and proliferate in the absence of strain. $^{32}$ In cells more than $1 \mathrm{~mm}$ from the wound edge, migration and proliferation are slight and these cells were hardly affected by mechanical strain. Mechanical strain may especially affect the cells that changed their polarity with cytoskeletal derangement. Thus our model represents an efficient method of examining and comparing the effects of mechanical strain on migrating and proliferating cells. These factors are possibly some of the reasons why mechanical strain inhibited the migration and proliferation of RGM1 cells during wound healing.

The cytoskeletal system plays an important role in cell migration and proliferation. A previous study suggested that cytochalasin B, which blocks the formation of F-actin, and wortmannin, a myosin light chain kinase inhibitor, inhibited wound healing and cell migration and proliferation in primary cultured gastric epithelial cells. ${ }^{830}$ In the present study, mechanical strain suppressed the formation of lamellipodia and filopodia, which are closely involved in the function of the cytoskeletal system, at the edge of cells around the wound. On the other hand, in cells remote from the wound edge, actin formation was not different between the control and experimental group. These results suggest that mechanical strain inhibited cytoskeletal reassembly and modelling (fig 7, point 5) in the proliferating and migrating cells. Therefore it was suspected that mechanical strain retarded cell migration and proliferation.

Extracellular matrix (ECM) (fig 7, point 4), as the ligand for integrin (fig 7, point 3 ), modulates gastric mucosal wound healing. In our previous study, the wound healing rate was different in each type of ECM. ${ }^{31}$ Integrin plays an important role in mediating signals from the 
Control

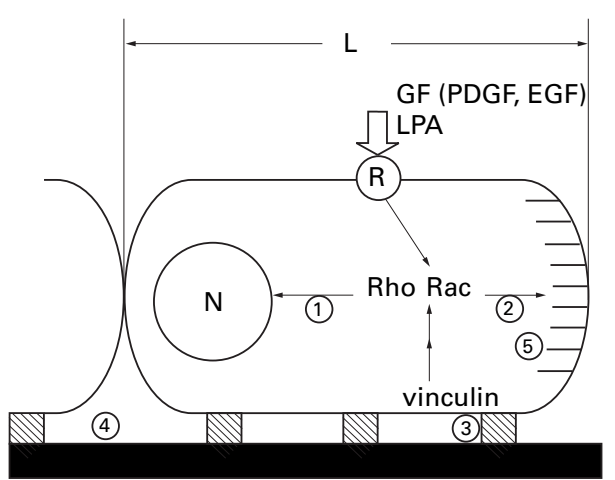

$10 \%$ strain

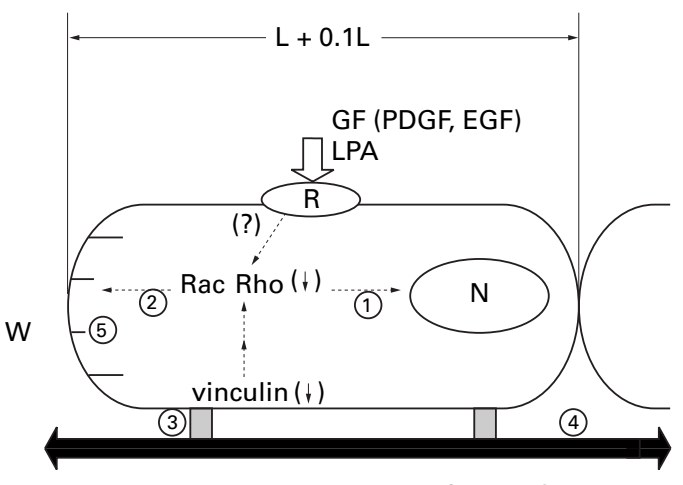

Stretch force

Figure 7 Schematic illustration for cellular migration and proliferation under conditions of strain. L, Length of adherence cell; $L+0.1 L$, the dimension of adherent cells is increased an average of $10 \%$ by mechanical strain; $N$, nucleus; W, wound; GF, growth factor; PDGF, platelet derived growth factor; EGF, epidermal growth factor; LPA, lysophosphatidic acid. 1, Signal transduction to the nucleus for cell division (proliferation); 2 , signal for cell movement via cytoskeletal system (migration); 3, integrin; 4, ECM (collagen type I); 5, lamellipodial formation.

ECM. Integrin aggregation and specific tyrosine phosphorylation result in focal accumulation of some signal transduction molecules, including RhoA, Rac1, Ras, Raf, mitogen activated protein kinase, extracellular signal regulated kinase, and JUN kinase besides focal adhesion kinase. This signal transduction (fig 7 , point 1 ) activates mitogen activated protein kinases and modulates cell proliferation and gene expression. ${ }^{34}$ Vinculin, talin, and $\alpha$-actinin, all adhesion plaque proteins, require both integrin aggregation and ligand occupancy for accumulation. Furthermore, if tyrosine phosphorylation proceeds, F-actin and associated cytoskeletal proteins accumulate. ${ }^{35}$ This signal transduction (fig 7 , point 2) suggests cell movement via the cytoskeletal system (migration). In the present study, the cells located around the wound were more intensely stained for vinculin, RhoA, Rac1, and lamellipodial formation than cells remote from the wound edge in controls. These migrating and proliferating cells were activated by integrin mediated signal transduction. On the other hand, in the experimental group, vinculin, RhoA, Rac1 and lamellipodial formation were poorly expressed compared with the control in the same area. The reason may be that repetitive stretching of basement membrane inhibited the integrin aggregation in only the migrating and proliferating cells.

Furthermore, the formation of integrin adhesion complexes is activated by Rho or Rac in response to growth factors and lysophosphatidic acid. ${ }^{36}$ The small GTP binding protein Rho family has emerged as key regulators of actin cytoskeleton. In small intestinal crypt cells, Rho are essential elements of the mechanism by which growth factors induce cell migration to restore mucosal integrity. ${ }^{37}$ Mechanical strain induces growth of neonatal rat smooth muscle cells and increases the autocrine response to platelet derived growth factor. ${ }^{38}$ In this experiment, it is not known whether mechanical strain therefore inhibits the appearance of RhoA and Rac1 via growth factor mediated signal transduction in cells located at the margin of the wound.
In summary, mechanical strain inhibited the migration and proliferation and suppressed the expression of lamellipodial formation, vinculin, RhoA, and Rac1 of cultured normal gastric mucosal RGM1 cells around the wound edge. The mechanical strain induced delay of cellular migration and proliferation may support the suggestion that a liquid diet accelerates the repair of gastric ulcers compared with a chow diet in vivo. ${ }^{2}$ Therefore, although many factors affect gastric ulcer healing, repetitive mechanical strain may directly influence retardation of gastric mucosal wound healing in vivo.

1 Minami H, McCallum RW. The physiology and pathophysiology of gastric emptying in humans. Gastroenterology 1984;86:1592-1610

2 Tsukimi Y, Okabe S. Acceleration of healing of gastric ulcers induced in rats by liquid diet: importance of tissue contraction. Fpn f Pharmacol 1994;66:405-12.

3 Dent J, Dodds WJ, Sekiguchi T, et al. Inter digestive phasic contractions of human lower esophagial sphincter. Gastroenterology 1983;84:453-60.

4 Kobayashi I, Kawano S, Tsuji S, et al. RGM1, a cell line derived from normal gastric mucosa of rat. In Vitro Cell Dev Biol $1996 ; 32 \cdot 259-61$.

5 Kinoshita Y, Nakata H, Sazzad H, et al. Gene expression of keratinocyte and hepatocyte growth factors during the healing of rat gastric mucosal lesions. Gastroenterology 995;109:1068-77.

6 Furukawa O, Nakamura E, Okabe S. Characterization of a novel cell damage model induced by acid and pepsin using gastric epithelial cells: protective effect of sucralfate. $\mathcal{f}$ Gastroenterol Hepatol 1997;12:115-21.

7 Tsuji S, Sawaoka H, Kawano S. Effect of NS-398, a specific inhibitor for cyclooxygenase-2, on gastric cell proliferation [abstract]. Gastroenterology 1995;108:A245.

8 Watanabe S, Hirose M, Yasuda T, et al. Role of actin and calmodulin in migration and proliferation of rabbit gastric cults in culture 7 Gastroenterol Hepatol 1994;9: 325-33.

9 Burridge K, Fath K. Focal contacts: transmembrane links between the extracellular matrix and the cytoskeleton. Bioessays 1989;10:104-8.

10 Burridge K, Fath K, Kelly $\mathrm{T}$, et al. Focal adhesions: transmembrane junctions between the extracellular matrix and the cytoskeleton. Annu Rev Cell Biol 1988;4:487-525.

11 Huttenlocher A, Sandborg RR, Horwitz AF. Adhesion in cell migration. Curr Opin Cell Biol 1995;7:697-706.

2 Clark EA, Brugge JS. Integrins and signal transduction pathways: the road taken. Science 1995;268:233-9.

13 Paterson HF, Self AJ, Garrett MD, et al. Microinjection of recombinant p21rho induces rapid changes in cell morphology. F Cell Biol 1990;111:1001-7.

14 Takaishi K, Kikuchi A, Kuroda S, et al. Involvement of rho p21 and its inhibitory GDP/GTP exchange protein (rho GDI) in cell motility. Mol Cell Biol 1993;13:72-9.

15 Kishi K, Sasaki T, Kuroda S, et al. Regulation of cytoplasmic division of Xenopus embryo by rho p21 and its inhibitory GDP/GTP exchange protein. F Cell Biol 1990;120:118795. 
16 Yoshioka K, Matsumura F, Akedo H, et al. Small GTP-binding protein Rho stimulates the actomyosin system, leading to

17 Hall A. Rho GTPases and the actin cytoskeleton. Science 1998;279:509-14

18 Banes AJ, Gilbert J, Taylor D, et al. A new vacuum-operated stress-providing instrument that applies static or variable duration cycle tension or compression to cells in vitro. $\mathcal{F}$ Cell Sci 1985;75:35-42.

19 Banes AJ, Link GVW, Gilbert J, et al. Culturing cells in mechanically active environment. American Biotechnology Laboratory 1990;8:12-22.

20 Rosales OR, Sumpio, BE. Changes in cyclic strain increase inositol triphosphate and diacylglycerol in endothelial cells. Am f Physiol 1992;262:C956-62.

21 Gratzner HG. Monoclonal antibody to 5-bromo- and 5-iodo-deoxyuridine: a new reagent for detection of DNA 5-iodo-deoxyuridine: a new reagent
replication. Science 1982;218:474-5.

22 Cooper JA, Blum JD, Pollard TD. Acanthamoeba castellaniii capping protein: properties, mechanism of action,
immunologic cross-reactivity, and localization. $f$ Cell Biol immunologic cross-

23 Asijee GM, Sturk A, Bruin T, et al. Vinculin is a permanent component of the membrane skeleton and incorporated into the (re)organizing cytoskeleton upon platelet activation. Eur F Biochem 1990;189:131-6.

24 Kwong NK, Brown BH,Whittaker GE, et al. Electrical activity of the gastric antrum in man. Br $\mathcal{F}$ Surg 1970;12:913-16.

25 Couturier D, Rose C, Paologgi J, et al. Electrical activity of the normal human stomach. A comparative study of recordings obtained from serosal and mucosal sides. Dig Dis Sci 1972;17:969-76.

26 Weber J, Kohatsu S. Pacemaker localization and electrical conduction patterns in the canine stomach Gastroenterology 1970;59:717-26.

27 Kelly KA, Code CF. Canine gastric pacemaker. Am f Physiol 1971;220:112-18.
28 Synnerstad I, Ekblad E, Sundler F, et al. Gastric mucosal smooth muscles may explain oscillations in glandular pressure: role of vasoactive intestinal peptide. Gastroenterolgy 1998;114:284-94.

29 Watanabe S, Xian-En Wang, Hirose M, et al. Basic fibroblast growth factor accelerates gastric mucosal repair in vitro by promoting mesenchymal cell migration and proliferation. $\mathcal{f}$ Gastroenterol Hepatol 1995;10:627-32.

30 Watanabe S, Xian-En Wang, Hirose M, et al. Effect of myosin light chain kinase inhibitor wortmannin on the wound repair of cultured gastric mucosal cells. Biochem Biophys Res Commun 1994;199:799-806.

31 Mikami H, Watanabe S, Hirose M, et al. Role of extracellular matrix in wound repair by cultured gastric mucosal cells. Biochem Biophys Res Commun 1994;202:285-92.

32 Watanabe S, Xian-En Wang, Hirose $M$, et al. Plateletderived growth factor accelerates gastric epithelial restoration in a rabbit cultured cell model. Gastroenterology 1996; 110:775-9.

33 Basson MD, Li GD, Hong F, et al. Amplitude-dependent modulation of brush border enzymes and proliferation by cyclic strain in human intestinal Caco-2 monolayers. 7 Cell Physiol 1996;168:476-88.

34 Chen Q, Kinch MS, Lin TH, et al. Integrin-mediated cell adhesion activates mitogen-activated protein kinases. $\mathcal{F}$ Biol Chem 1994;269:26602-5.

35 Miyamoto S, Teramoto $\mathrm{H}$, Coso OM, et al. Integrin function: molecular hierarchies of cytoskeletal and signal molecules. F Cell Biol 1995;131:791-805.

36 Machesky LM, Hall A. Role of actin polymerization and adhesion to extracellular matrix in Rac- and Rho-induced cytoskeletal reorganization. $\mathcal{F}$ Cell Biol 1997;138:913-26.

37 Santos MF, McCormack SA, Guo Z, et al. Rho proteins play a critical role in cell migration during the early phase of mucosal restitution. F Clin Invest 1997;100:216-25.

38 Emily W, Qing M, Krishnankutty S, et al. Mechanical strain induces growth of vascular smooth muscle cells via autocrine action of PDGF. 7 Cell Biol 1993;123:741-7. 